\title{
As redes sociais como ferramenta de recrutamento e seleção
}

O artigo tem como finalidade explorar o papel e as possibilidades do uso das redes sociais nos processos de recrutamento e seleção em organizações. Logo, este trabalho tem como objetivo geral, analisar se as empresas têm utilizado as redes sociais enquanto instrumento de recrutamento e seleção, ao apontar suas vantagens e dificuldades. Além de destacar as principais redes utilizadas pelas agências de recrutamento e seleção, suas metodologias de triagem, bem como as características avaliadas, pelos mesmos, ao escolherem, estrategicamente, entre os candidatos, o que melhor se adequa a vaga ofertada. Nesse sentido, através da produção deste trabalho, foi possível explanar sobre as vantagens destas ferramentas para o departamento de recursos humanos, e também, abordar sobre o marketing pessoal necessário aos eventuais candidatos dispostos no mercado de trabalho. Para atingir o objetivo geral deste artigo e avaliar a aplicabilidade das redes sociais no processo de recrutamento e seleção nas empresas da região do Cariri, o artigo traz uma pesquisa de campo para coleta e avaliação de dados seguindo os apontamentos discorridos no referencial teórico.

Palavras-chave: Redes sociais; TIC's; Recrutamento; Seleção.

\section{Social networks as a tool for recruitment and selection}

The article aims to explore the role and possibilities of using social networks in recruitment and selection processes in organizations. Therefore, this paper aims to analyze whether companies have used social networks as an instrument of recruitment and selection, pointing out their advantages and difficulties. In addition to highlighting the main reuses used by the recruitment and selection agencies, their screening methodologies, as well as the characteristics evaluated by them, when choosing, strategically, among the candidates, which best suits the vacancy offered. In this sense, through the production of this work, it was possible to explain the advantages of these tools for the human resources department, as well as to address the personal marketing necessary to the willing candidates in the job market. In order to reach the general objective of this article and to evaluate the applicability of social networks in the recruitment and selection process in the companies of the Cariri region, the article presents a field research for the collection and evaluation of data following the notes discussed in the theoretical framework.

Keywords: Social networks; TIC's; Recruitment; Selection.

Topic: Recursos Humanos

Reviewed anonymously in the process of blind peer.
Received: 12/01/2019

Approved: 23/04/2019
Andressa Cruz Pereira Silva

Centro Universitário Dr. Leão Sampaio, Brasil.

http://lattes.cnpq.br/8469572321704905

andressa.adm13@hotmail.com

\section{Joyce da Silva Albuquerque}

Universidade de Fortaleza, Brasil.

http://lattes.cnpq.br/0230789161277092

joyce@leaosampaio.edu.br

\section{Referencing this:}

SILVA, A. C. P.; ALBUQUERQUE, J. S.. As redes sociais como ferramenta de recrutamento e seleção. Business Journal, v.1, n.1, p.18-35, 2019. DOI: http://doi.org/10.6008/CBPC2674-6433.2019.001.0002

DOI: 10.6008/CBPC2674-6433.2019.001.0002 


\section{INTRODUÇÃO}

Para além de uma mera ferramenta pessoal, as redes sociais tem complementado o processo de recrutamento e seleção. Hoje, as redes sociais abriram a possibilidade de avaliar, antes de uma entrevista, aspectos mais pessoais do candidato, objetivos de vida e carreira, rede de contatos estabelecida, aspirações e entre outros relevantes aspectos. Ao contrário da realidade anterior a ascensão das redes, o qual se verificava apenas o currículo de um profissional para analisar e, talvez, a referência de alguém que indicava esse profissional no início de um processo seletivo. Nesse sentido, informações negativas ou fotos inadequadas, em perfis de redes sociais, podem influenciar na avaliação de um candidato, mesmo que ele seja qualificado e possua um ótimo currículo.

Logo, ao considerar a globalização, a internet, na contemporaneidade, assume um importante papel no cotidiano das pessoas, pois as redes sociais têm possibilitado chegar mais facilmente a um contato e identificar possíveis candidatos (virtualmente) que talvez, não responderiam a um anúncio de emprego tradicional. Com isso, o processo de busca de profissionais tornar-se mais rápido e as etapas seguintes de um processo seletivo são cumpridas em um menor espaço de tempo e menores custos (FRAGOSO, 2017).

É salutar que as redes sociais apresentam-se como um recurso a mais para compor o processo de recrutamento, que não deverá dispensar um aprofundamento do contato inicial, quando o recrutador, em reuniões pessoais com o candidato, poderá checar as informações inicialmente levantadas e perceber se, efetivamente, trata-se de um perfil relevante.

Outro aspecto positivo no recrutamento pelas redes sociais é que a própria empresa, ao utilizá-las para divulgar suas oportunidades de trabalho, poderá apresentar suas políticas e processos, cultura, objetivos organizacionais, interesses e desafios, atraindo candidatos e afastando aqueles que não se identificam com a companhia.

A atividade de seleção de pessoas se torna um momento estratégico na busca por talentos (capital intelectual), que agreguem valor e a utilização das TIC'S tecnologias de informação e comunicação proporcionam maior facilidade de socializar informações de forma continua, crescente e imensurável. Deste modo, surge como problemática deste trabalho: As empresas têm utilizado as redes sociais enquanto instrumento de recrutamento e seleção?

Para tal indagação da pesquisa, adotou-se como objetivo geral, analisar se as empresas têm utilizado as redes sociais enquanto instrumento de recrutamento e seleção. Além de explorar, nos objetivos específicos, o papel e as possibilidades de uso das redes sociais nos processos de recrutamento e seleção em organizações. Em que é possível analisar referente aos mesmos, quais as principais dificuldades em recrutar pelas redes sociais. Apontar quais as principais vantagens das redes sociais como ferramenta de recrutamento e seleção. E também, abordar quais redes sociais são mais utilizadas e como ocorre este processo. Este estudo fomenta a reflexão sobre as transformações da era tecnologia ao impactar as organizações e como utilizar-se dos recursos disponíveis para potencializar o trabalho dos profissionais de recursos humanos, especificando a atividade de recrutamento e seleção. 
Este trabalho se torna relevante por analisar o contexto contemporâneo ao inserir a modernidade no meio empresarial, gestão de tempo e praticidade pelas mídias de internet. O advento tecnológico e de informatização tem modificado os processos de seleção quanto à área de captação e seleção de candidatos nas empresas, gerando mudanças na forma de fazer suas ofertas no mercado de trabalho e de recursos humanos. Assim, por meio desta análise gestores, estudantes e demais públicos interessados nessa temática poderão se atualizar quanto à inserção das redes sociais nos processos de recrutamento e seleção.

\section{REVISÃO TEÓRICA}

\section{Recrutamento e seleção de talentos}

A área de recrutamento e seleção (R\&S) é cada vez mais estratégica e fundamental nas organizações, na medida em que tem o desafio de encontrar os melhores profissionais para as funções solicitadas em cada vez menos tempo e com uma grande qualidade e assertividade (REIS, 2010). Esses são aspectos fundamentais para uma gestão de talentos com eficácia para as necessidades das organizações.

Segundo Caetano et al. (2007): “O recrutamento é visto como o atrair dos potenciais candidatos, enquanto a seleção diz respeito a todo o processo, desde a convocação dos pretensos candidatos até a decisão última de admissão". Fazendo uma diferenciação conceitual, ao falar de seleção, Martins (2007) afirma que este processo consiste na comparação entre perfis dos candidatos e os requisitos do cargo, sendo assim, o ideal é que o perfil e o cargo se ajustem. Deste modo, é essencial que se escolha a pessoa certa para o cargo certo, objetivando, assim, manter ou aumentar a eficiência e desempenho do pessoal.

Ao destacar os objetivos na utilização das redes sociais nos processos de Recrutamento e Seleção, as ações nas redes sociais são consideradas importantes nesse processo, pois são submetidas à observação e análise de comportamento do candidato nas redes sociais, no momento que possibilitar o acesso ao perfil, dos potenciais candidatos, no ambiente online. A fase de Recrutamento por mídias sociais, também possibilita a facilidade no envio de currículos, facilidade na procura de emprego. "Este é o papel do recrutamento: divulgar no mercado as oportunidades que a organização pretende oferecer para as pessoas que possuam determinadas características desejadas" (CHIAVENATO, 2010).

As empresas especializam-se de forma crescente e procuram pessoas cujo seu potencial corresponda às suas necessidades "Atualmente as empresas têm procurado pessoas eficazes e dinâmicas, capazes de aumentar a perspectiva de vida das empresas e, consequentemente, alcançar o sucesso. Os objetivos organizacionais só podem ser atingidos por intermédio dos seus colaboradores" (GUIMARÃES et al., 2005).

O processo de recrutamento envolve várias fases, nomeadamente: identificação das necessidades de recrutamento, a análise e definição de funções, a prospecção interna e/ou externa, definição de objetivos que o titular vai prosseguir, definição de tarefas e responsabilidades, e, finalmente, a triagem de candidatos.

Para pensar os conceitos de recrutamento e seleção separadamente, Marras (2000) define recrutamento como uma atividade de captação de pessoas interna e externamente à organização. O processo de seleção é feito após o recrutamento, as atividades consistem em etapas diferentes que se 
complementam, como afirma Chiavenato (2010), enquanto o recrutamento é um mecanismo de atração, divulgação e comunicação, uma atividade convidativa, em contraponto, a seleção é uma atividade de escolha, classificação e decisão, sendo assim ela é restritiva.

As empresas concebem a notória importância e valor ao processo de recrutamento e seleção de pessoas que irão compor o quadro de funcionários necessários aos cargos dispostos. "Atualmente, em um mundo de negócios onde há competitividade no mercado, as empresas estão recrutando e selecionando profissionais que venha agregar valores e aumentar sua posição no ambiente econômico a um nível de excelência interna e externa" (BAYLÃO et al., 2014).

Nessa mesma perspectiva, Chiavenato (2010) afirma que recrutamento e a seleção fazem parte de um processo maior que é o de suprir e prover a organização de talentos e competências necessários à sua continuidade e sucesso em um contexto altamente dinâmico e competitivo. $\mathrm{O}$ autor ainda destaca que o recrutamento não pode ser visto como uma atividade isolada da estratégia da empresa, pois como os negócios mudam e surgem novas necessidades a cada dia, torna-se essencial contar pessoas flexíveis capazes de adaptar-se a mudanças constantes.

Os conceitos de Recrutamento e Seleção são a chave principal de todos os temas de Gestão de Recursos Humanos, baseando-se na integração de processos dinâmicos e interativos. A escolha das pessoas certas se torna vital para o funcionamento das organizações, nesse sentido, o mercado de trabalho atual, procura profissionais que articulem competências técnicas e comportamentais. Competências como a comunicação, o relacionamento interpessoal, a cooperação, a habilidade de lidar com mudanças, a capacidade de solucionar problemas e conflitos, além de uma visão sistêmica e empreendedora que têm sido o diferencial na escolha dos candidatos (ZANUTO, 2010).

As funções de um gerente e particularmente de um responsável pelo departamento de $\mathrm{RH}$ são um dos pilares de uma organização. A eficácia no desempenho de um gerente depende da descoberta e atração de indivíduos que tenham a capacidade e a motivação ideais, ou seja, boa parte da eficácia do gerente depende diretamente da eficácia da sua equipe (ZANUTO, 2010).

Antes do Recrutamento, em sequência a Seleção do Pessoal, deve ser montado um perfil da vaga, para que se possa atender melhor às necessidades da organização. Com processos de recrutamento e seleção bem estruturados, a medida em que se faz uma triagem de candidatos, é possível conseguir integrar na organização pessoas talentosas, com o perfil ideal para ocupar e desempenhar a função (CHIAVENATO, 2010). O capital humano tem relevância estratégica, uma vez que, os profissionais, têm capacidade de gerar, através do conhecimento, soluções inteligentes (criar valor e obter resultados) em relação a serviços (bem como produtos), que atendam às necessidades e/ou expectativas dos clientes.

\section{TIC'S, redes sociais e perfil dos candidatos.}

O recrutamento pelas redes sociais é uma tendência, a triagem de currículos por meio de redes sociais é cada vez mais comum. Os Gestores/responsáveis procuram efetivamente informação nas redes sobre os potenciais funcionários, onde são verificadas as diversas mídias sociais informativas, tais como o Linkedin, enquanto uma rede profissional, o Facebook, para visualizar e analisar comportamentos sociais, e 
o Curriculum Lattes, em uma perspectiva de trajetória profissional e acadêmica. Para o recrutador ou empregador, a maior vantagem de redes como o Linkedin é a ampla oferta de candidatos em potencial (FRAGOSO, 2017).

A tecnologia nada mais é que um suporte digitalizado da informação e da comunicação, que proporciona rapidez e interesse mediante o rápido acesso entre o indivíduo e a informação. Essa nova dimensão das Tecnologias da Educação e Comunicação deve [...] permitir-nos compartilhar nosso conhecimento e apontá-los uns para os outros. (BREITENBACH, 2012)

De acordo com Lemos (2005), a tecnologia propicia maior mobilidade nas formas de comunicação, alterando as relações humanas que passam a se tornar na maior parte do tempo, virtuais, como se fossem inerentes a sua natureza comunicativa. Fundamentado nesse pensamento, pode-se depreender que a tecnologia está presente em quase todos os aspectos da nossa vida. "As tecnologias sem fio, como os celulares e as formas de conexão Wi-Fi à internet, têm criado novas práticas de mobilização social nas metrópoles contemporâneas. A era da conexão relaciona assim tecnologia digital, comunicação, massa, multidão, mobilidade e conexão" (LEMOS, 2005).

O avanço tecnológico e a propagação em grande velocidade do uso utensílio virtual afetam diretamente as formas de comunicação e interação dos indivíduos, visto que podem trazer benefícios para a maneira de nos relacionarmos socialmente, viabilizando ao mesmo tempo rapidez na comunicação, troca de informações instantâneas e entretenimento. Considerando que uma imensa parte da população possui acesso a estes meios para obter o máximo de mobilidade, pode conceber os mesmos como uma necessidade. "Agora a internet móvel está aproximando o homem do desejo de ubiquidade fazendo emergir uma nova cultura telemática, com novas formas de consumo de informação e com novas práticas de sociabilidade" (LEMOS, 2005).

Nesse contexto, é essencial ter um departamento de Recursos Humanos preparado, atualizado e capacitado, para enfrentar o desafio de atrair e reter talentos, ao formar e manter equipes de alto rendimento, possibilitando aperfeiçoar os processos internos, ganhando agilidade, qualidade e, principalmente, mais assertividade. Logo, algumas ferramentas tecnológicas e estratégias disponíveis no mercado, podem ser muito úteis para padronizar os procedimentos, integrar informações e multiplicar conhecimentos na gestão de RH. Para Chiavenato (2010), a internet veio para revolucionar o processo de recrutamento, devido à praticidade de interação na relação candidato/empresa que ela proporciona. Dessa forma, Castells (2003) vem confirmar a importância das TIC's:

[...] se a tecnologia da informação é hoje o que a eletricidade foi na Era Industrial, em nossa época a internet poderia ser equiparada tanto a uma rede elétrica quanto ao motor elétrico, em razão de sua capacidade de distribuir a força da informação por todo o domínio da atividade humana. Ademais, à medida que novas tecnologias de geração e distribuição de energia tornaram possível à fábrica e a grande corporação como os fundamentos organizacionais da sociedade industrial, a internet passou a ser a base tecnológica para a forma organizacional da Era da informação: a rede. (CASTELLS, 2003)

As redes sociais se tornaram um excelente canal de contato entre candidatos e empresas, ultrapassando suas funções iniciais voltadas para lazer e entretenimento. "À medida que a linha entre a vida pública e a vida privada se torna mais desfocada, os empregadores começam a examinar a informação disponível nas RS, que podem não ser idealizadas através da análise do CV (Curriculum Vitae) ou na realização 
de uma entrevista" (FRAGOSO, 2017). O LinkedIn, por exemplo, cujo principal objetivo é conectar profissionais, pode ser utilizado como uma ferramenta de recrutamento. É uma rede direcionada para o mundo corporativo em que o seu público-alvo é composto por utilizadores que procuram a promoção e divulgação dos seus perfis profissionais.

A participação nesta rede tornou-se quase obrigatória para quem aspira evoluir profissionalmente e tem cerca de 433 milhões de utilizadores em todo o mundo (MARQUES, 2017). Rozenblum (2012) define a rede online como um serviço que permite que os indivíduos criem e compartilhem o seu perfil em páginas de internet, perfil este que contém informações de localização, interesses, atividades, educação, emprego, além de fotos, pensamentos, sentimentos e status de relacionamento.

O Linkedln ainda detém a maior parte das informações que empresas precisam a respeito dos seus candidatos. Também existem no mercado softwares especialmente desenvolvidos para ajudar a escolher o melhor profissional para a vaga disponível (ROZENBLUM, 2012). Sendo necessário escolher um que melhor se adapte às necessidades da sua empresa e usá-lo no processo de seleção.

Diante das exposições teóricas é possível enumerar vantagens que o uso das redes sociais para recrutar e selecionar candidatos possibilita: o maior número de candidatos alcançados, a diminuição de custos, a agilidade do processo e a pesquisa mais direcionada ao perfil de candidato desejado. Por outro lado, os autores também identificam desvantagens, tais como: o excesso de candidaturas que pode atrasar o processo, as informações apresentadas no perfil online podem estar incompatíveis com a realidade, o risco do plágio pelos candidatos que podem utilizar currículos disponíveis na rede para construir o seu próprio e a impessoalidade.

\section{As principais ferramentas online utilizadas pelos gestores para os processos de recrutamento e seleção}

A tecnologia possibilitou o 'esquecimento' da distância, ou seja, esta já não é mais um empecilho na comunicação. A internet propicia a divulgação de uma massa de informações gigantesca, e as redes sociais, além desta função, modificam e criam uma linguagem própria, compartilham ideias rapidamente e proporcionam a interação com um grande número de pessoas instantaneamente. Considerando a internet e as redes sociais os meios de comunicação que se desenvolveram em menor tempo em comparação a outros, que atingiram maior quantidade de usuários e que possuem tendência a se desenvolverem ainda mais com o tempo. Pierre Lévy (2010 citado por BREITENBACH, 2012) afirma que: "A Internet é um instrumento de desenvolvimento social. Devemos lembrar que a escrita demorou pelo menos 30.000 anos para atingir o atual estágio, no qual todos sabem ler e escrever. A Internet tem apenas 10 anos".

Com a propagação do acesso à internet e Mídias Sociais, a quantidade de informações pessoais, profissionais e comportamentos disponíveis de cada indivíduo tende a aumentar na rede (ARAÚJO, 2012). De acordo com o mesmo autor, nas redes sociais focadas em relacionamento não profissional é possível verificar aspectos do perfil pessoal do candidato. O recrutador quer saber como o profissional se comporta e se articula nas redes sociais. Afinal, o universo digital oferece informações a respeito de um possível representante da empresa. É nesse sentido que as redes sociais funcionam como uma plataforma de 
networking da atualidade que está diretamente ligada ao marketing pessoal. Assim, aspectos negativos nos perfis seriam suficientes para desclassificar um candidato no processo seletivo.

O uso adequado das redes sociais, portanto, pode alavancar uma carreira. A publicação de informações verdadeiras, dicas profissionais, trabalhos acadêmicos, projetos, experiências profissionais, currículo, enfim, dados que valorizam o perfil de uma pessoa podem ser decisivos num processo de triagem a uma vaga de emprego. Por outro lado, fotos e comentários inapropriados podem prejudicar o candidato. Cabe ao candidato ter isso em mente e tentar promover um marketing pessoal virtual que possa torná-lo mais atraente para um recrutador, uma vez que já é bem sabido que no ambiente digital, as boas ideias e ações conseguem visibilidade e apoio de forma muito rápida e espontânea (ARAÚJO, 2012).

Logo, Lemes (2015) vem dissertar sobre a rede social como ambiente informal, mas também, profissional, possibilita compartilhar insights sobre sua área de atuação e assuntos relacionados ao trabalho, sendo uma oportunidade de ampliar a rede de relacionamento, o que pode fomentar, para o trabalho, uma oferta futura. Em um contexto onde as organizações exigem uma pesquisa mais aprofundada sobre os candidatos na etapa final da seleção, as redes sociais são acessadas como fonte complementar de informação.

Em seus perfis virtuais, os candidatos expõem suas opiniões, valores, preconceitos e traços de suas personalidades. Essas informações podem ser usadas como forma de avaliação pelos recrutadores que irão julgar se o conteúdo exposto condiz com o perfil desejado pela empresa. [...] Em seus perfis virtuais, os candidatos expõem suas opiniões, valores, preconceitos e traços de suas personalidades. Essas informações podem ser usadas como forma de avaliação pelos recrutadores que irão julgar se o conteúdo exposto condiz com o perfil desejado pela empresa (LEMES et al., 2015).

Enquanto estratégia inovadora ao utilizar a tecnologia, o processo de recrutamento online consiste na triagem, identificação e avaliação dos candidatos através de ferramentas da internet. Os sistemas de recrutamento permitem armazenar currículos online e selecioná-los por palavras-chave ou por outros critérios, como cargos e competências. Assim, transformam o currículo em papel em informações virtuais dos candidatos e possibilitam fácil acesso aos dados por todo o processo de recrutamento e seleção (GIRARD et al, 2010).

À priori, o recrutamento online ou 'e-recrutamento' é entendido como um método que objetiva somente a atração de talentos, isto é, divulgação das vagas pela internet, por outro lado, há autores que conceituam esta prática como uma técnica, não somente de atração de candidatos, mas também gestão de base de dados, triagem dos currículos e o início do uso de ferramentas avaliativas. A grande vantagem do recrutamento online prende-se com a possibilidade de os candidatos publicarem e divulgarem informação sobre o seu percurso profissional, experiências e objetivos de carreira de forma permanente, durante 24 horas por dia e de forma global. O Facebook é a prova disso, pois é a rede mais popular do planeta, com mais de 750 milhões de utilizadores em todo o mundo, segundo (FREITAS, 2017).

Dentre os principais motivos, obtidos em redes sociais, que influenciam uma empresa a contratar um candidato, estão: mostras de que o candidato é criativo, realiza trabalhos voluntários, possui habilidades de comunicação sólidas ou boas referências postadas por outros. Além disso, se o perfil do candidato causa uma impressão positiva de sua personalidade e habilidade organizacional, ou fundamenta suas qualificações profissionais e acadêmicas, as chances de contratação são maiores. (ARAÚJO, 2012) 
O recrutamento on-line não se remete apenas em comunicação de vagas através da Internet, mas também, todas as ferramentas tecnológicas para realização e a triagem de currículos, a fim de manter um banco de dados atualizado e eficiente na busca por características específicas, o feedback on-line, bem como modernas formas de avaliação (MITTER et al., 2005).

Nas análises das redes, o Linkedin é facilmente associado a gama de informações voltadas ao perfil profissional dos candidatos, permitindo que as agências os selecionem com base nas suas formações profissionais. Já o Facebook e o Twitter (sites de relacionamentos pessoais) são utilizados para respaldar informações pessoais prestadas durante o processo seletivo e permitem às agências conhecer as reais características do candidato em seu convívio social postadas em seu perfil na internet. (ALMERI et al., 2013)

Os perfis disponíveis dos candidatos podem aumentar as hipóteses de ser considerados em um processo de R\&S, quando fornecem provas de suporte das suas qualificações, retratando um perfil indicativo de facilidade de integração, exibindo criatividade, habilidades positivas de comunicação e/ou a exibição de recomendações de anteriores empregadores ou colegas. Os recrutadores reagem negativamente a palavrões, erros de gramática e pontuação e posts com referências ao consumo de álcool (JOBVITE, 2013). No mesmo sentido, Matos (2012) afirma sobre a importância da análise das redes sociais nos processos seletivos:

[...] ajudam a complementar as informações sobre os candidatos e a esclarecer mais sobre suas personalidades - sempre levando em conta, e respeitando, o limite de cada rede. Assim, no Facebook, por exemplo, a empresa observa os interesses do candidato, sua forma de expressar temas estressantes para sua vida e observa se a exposição dele é saudável ou não (MATOS, 2012).

É possível destacar que um dos maiores malefícios do excesso de exposição pessoal é a perda de oportunidades no mercado de trabalho, pelo fato das agências ao observarem as redes sociais destes usuários, acabam por se desinteressar em convocá-los para possíveis processos de recrutamento e seleção, devido a uma imagem negativa demonstrada por ele próprio, fazendo com que seu perfil não se enquadre no que procuram para a vaga disponível. De acordo com Almeri et al. (2013) as características de um perfil inadequado são: Erros de digitação, concordância ou ortografia ao postar; Exposição excessiva de informações pessoais e desnecessárias; Demonstração de tendências preconceituosas e ofensivas; Difamar a imagem das empresas em que já trabalhou; Postar informações falsas a respeito de suas intenções ou demonstrar ambiguidade nos objetivos profissionais; Demonstrar personalidade contundente em discussões polêmicas como futebol, política e religião; Demonstrar um comportamento violento ou promíscuo com os amigos; Fazer parte de comunidades que possam denegrir a sua imagem perante os olhares de terceiros.

Dessa forma, o processo de R\&S prioriza o conteúdo pessoal postado pelo usuário como, por exemplo, a forma que estes definem quem são, como expressam suas ideologias e defendem seus pontos de vistas em comentários no próprio perfil ou de terceiros, se possuem um nível ortográfico e de vocabulário considerável, a ponto de elaborar um perfil com informações dispostas de maneira clara e coerente (ALMERI et al., 2013), além disso, os autores ainda afirmam que as características do perfil adequado do profissional nas redes sociais são: Cuidado e preservação a imagem pessoal nas redes sociais virtuais; Clareza, objetivo e coerência nas postagens; Promoção de um perfil profissional nas redes socais virtuais; Demonstração de interesse e boa vontade em aprender; Utilização da rede social de maneira participativa; Flexibilidade e 
adaptabilidade ás mudanças cotidianas no conteúdo postado; Interação nas redes sociais virtuais de maneira sadia.

A utilização de serviços on-line podem criar grandes oportunidades de ingresso no mercado de trabalho hoje em dia, onde as empresas estão cada vez mais engajadas no seu marketing relacional e outros métodos de atrair potenciais candidatos a uma vaga na empresa (CAPELLI, 2001). O funcionário ideal ao cargo pode estar em outro estado, cidade ou até mesmo impossibilitado de comparecer pessoalmente no escritório, também ocorre nos casos em que as empresas possuem seu Departamento de Recursos Humanos na capital de determinado estado e a empresa deseja realizar um processo seletivo para suprir uma carência de funcionários em munícipios do interior, onde possuem filiais. Diante desta realidade, empresas de recrutamento e seleção têm optado por fazerem entrevistas online, através de ferramentas como o Skype.

O uso da Inteligência Artificial fornece um relatório preciso do nível de adequação dos candidatos à vaga. Essas informações podem ser usadas na escolha dos currículos, na realização das entrevistas e na formação de um banco de talentos para as próximas contratações. Um candidato pode ser favorecido ou prejudicado por impressões subjetivas do selecionador.

O uso da Inteligência Artificial na triagem diminui esse ruído, avaliando o profissional pelas habilidades que ele realmente apresenta, assim, com transparência de dados e insumos, para melhor tomada de decisões, as contratações são mais precisas. As empresas têm se utilizado de mídias digitais para o processo de recrutamento e seleção, isso abrange desde o cadastramento de currículos em sites específicos ou até páginas em redes sociais, onde isso por si só demonstra um pouco do conhecimento de tecnologia exigido por qualquer empresa atualmente, além disso, as empresas podem comparar a veracidade dos fatos colocados em um currículo comparando com as das informações postadas nas mídias conforme (AFONSO, 2009).

\section{O impacto das redes sociais nas relações interpessoais e de trabalho}

Os avanços tecnológicos têm promovido mudanças sociais e, consequentemente, afetando o modo de gerir pessoas nas organizações. A popularização das redes sociais virtuais está transformando a forma como as empresas interagem com a sociedade. Atualmente, as organizações não utilizam as redes apenas como meio de divulgação, mas também como uma ferramenta decisiva no Recrutamento e Seleção (R\&S) de talentos. Dentre as funções da rede social virtual, Lorenzo-Romero (2011) afirma que as redes oferecem aos indivíduos um espaço para criar um perfil público e interagir com outras pessoas à distância, compartilhar informações, colaborar na geração de conteúdo, participar de movimentos sociais e correntes de opinião.

$\mathrm{Na}$ área de Gestão de Recursos Humanos (GRH), essas mudanças podem ser verificadas, por exemplo, pela adoção de redes sociais como meio de comunicação e acesso ao mercado de trabalho. Na década de 90 , surge a primeira rede social, o Classmates.com, possibilitando a extensão da vida pessoal ao mundo virtual. Em 2003, surge o Linkedin e as redes sociais se estendem ao cenário profissional e se reconfiguram como um importante meio de networking. (CASSIANO et al., 2016)

As mídias sociais se tornaram uma nova forma de projetar a imagem pessoal e profissional de um indivíduo. Pierre Levy (2002) explica que as comunidades virtuais são uma nova forma de fazer sociedade. 
Estas mídias permitem que o usuário cadastre certos dados, assim como fotos e vídeos, de modo que esses dados possam ser acessados por todos os outros usuários do serviço, de maneira restrita ou não. Além disso, o que os torna especialmente atraentes, é a possibilidade de integrar aos seus dados às páginas de dados pessoais de amigos e conhecidos, criando assim uma rede de relacionamentos, através da qual é possível aumentar seus contatos através dos contatos de outras pessoas (MIRA et al., 2011). Nesse sentido, "uma rede social é sempre um conjunto de atores e suas relações" (RECUERO, 2009). Embasados nesta perspectiva, os mesmos autores trazem uma análise sociológica sobre o impacto das redes nas relações interpessoais.

O ator social de uma rede social virtual é alguém que utiliza os serviços de uma Rede Social Virtual para, através dela, criar suas conexões e alimentar seu capital social. Conexões seriam os laços criados entre os Atores, ou seja, as pessoas ou comunidades a quem o ator está ligado ou associado (Wasserman e Faust, 1994). Já o capital social, segundo Bourdieu (1983) seria o conjunto de recursos potenciais que estão presente nas relações entre as pessoas, associadas a uma determinada coletividade. O capital social emerge das interações coletivas. Portanto, os Atores interagem através de conexões a fim de gerar capital social (MIRA et al., 2011).

Essas mídias sociais estão presentes na vida organizacional e este trabalho avalia sua influência no momento da contratação dos trabalhadores, para os profissionais de RH, as mídias sociais constituem um recurso complementar às técnicas de recrutamento e seleção, geralmente postas em prática no momento de adquirir um novo colaborador. Visto que provoca a redução do tempo de processamento e aperfeiçoa a checagem de informações, além de reduzir a quantidade de profissionais necessários para as atividades operacionais. Nesse sentido a tecnologia é considerada aliada por gerar ferramentas eficazes na captação dos candidatos.

As redes são virtuais, mas também reais, técnicas e sociais, portanto são dinâmicas. Elas incluem em si mesmas um movimento social de dinâmicas, ao mesmo tempo locais e globais, o que indica um efeito das forças de globalização em um mundo que se apresenta cada vez mais como interdependente e intercomunicativo.

As tendências globalizantes da modernidade são simultaneamente extensionais e intencionais - elas vinculam os indivíduos a sistemas de grande escala como parte da dialética complexa de mudança nos pólos local e global. Muitos dos fenômenos frequentemente rotulados como pós-modernos na verdade dizem respeito à experiência de viver num mundo em que a presença e ausência se combinam de maneiras historicamente novas. (GIDDENS, 1991)

Segundo Castells (1999), as redes constituem "a nova morfologia social de nossas sociedades, e a difusão da lógica das redes modifica de forma substancial a operação e os resultados dos processos produtivos e de experiência, poder e cultura". Ou seja, configuram-se como a nova forma de organização social. Em seu discurso, o autor afirma ainda que, as redes são estruturas abertas que tendem a se expandir, gerando novos 'nós', que compartilham os mesmos códigos de comunicação, enfatizando a necessidade lógica de estar-em-rede: para não sucumbir é preciso estar nas redes.

[...] provavelmente nenhum outro método tenha tido um efeito tão revolucionário nas práticas de recrutamento organizacional como a internet, para o mesmo autor, são várias as razões da popularização deste método, sendo no ponto de vista da empresa uma alternativa relativamente barata para atrair candidatos qualificados e para os candidatos, a internet oferece uma grande possibilidade de busca de emprego, pois pode ser feita em qualquer lugar do mundo e junto a um número considerável de empresas. (LEMES, 2014) 
A profunda transformação econômica e social das últimas décadas traz consigo a demanda acelerada pela inovação e seus impactos visíveis na adaptação das empresas e instituições a novas contingências interna e externas. No contexto atual, inovar não é uma opção, mas um imperativo da competitividade (ZANUTO, 2010).

A difusão das tecnologias da informação, embora sem dúvida dispense trabalhadores e elimine alguns postos de trabalho, não resultou e provavelmente não resultará em desemprego em massa no futuro previsível, porém, as relações sociais de trabalho sofreram uma transformação profunda. (CASTELLS, 1999)

As redes possibilitadas pela internet estão sendo usadas, gerando novas maneiras de participação política, novas formas de entretenimento, novas formas de contato social e relações de trabalho desde a contratação.

Nesse sentido, a sociedade em rede representa, para Castells (1999), "uma transformação qualitativa da experiência humana", visto que, este sociólogo é um pioneiro quando se trata de pesquisar os reflexos da sociedade em rede na economia e na convivência social em todo o mundo, a partir do fenômeno da internet. A sociedade em rede constitui a trama social e tecnológica em que vivemos, em todas as dimensões e em todas as práticas. Há uma nova estrutura social cujo funcionamento depende de tecnologias digitais de informação e comunicação.

[...] uma rede, assim, é uma metáfora para observar os padrões de conexão de um grupo social, a partir das conexões estabelecidas entre os diversos atores. A abordagem de rede tem, assim, seu foco na estrutura social, onde não é possível isolar os atores sociais e nem suas conexões. O estudo das redes sociais na internet, assim, foca o problema de como as estruturas sociais surgem, de que tipo são, como são compostas através da comunicação mediada pelo computador e como essas interações mediadas são capazes de gerar fluxos de informação e trocas sociais que impactam suas estruturas. (RECUERO, 2009)

Diante da velocidade da tecnologia, das possibilidades de suas redes, conexões e consequentes intervenções na sociabilidade global, consequentemente, a rede é uma realidade generalizada para a vida cotidiana, as empresas, o trabalho, a cultura, a política e os meios de comunicação. Segundo Castells (2015) entramos plenamente em uma sociedade digital (não o futuro, mas o presente) e teremos que reexaminar tudo o que sabíamos sobre a sociedade industrial, porque estamos em outro contexto. Segundo Castells (1999), em “A era da informação", surge uma nova sociedade quando uma transformação estrutural puder ser observada nas relações de produção, de poder e de experiência, estas conduzem a uma modificação também substancial das formas sociais de espaço e tempo e ao aparecimento de uma nova cultura.

\section{METODOLOGIA}

A seguinte pesquisa é de cunho qualitativo, buscando identificar como as empresas têm utilizado as redes sociais enquanto instrumento de recrutamento e seleção. Os estudos denominados qualitativos têm como preocupação fundamental o estudo e a análise do mundo empírico em seu ambiente natural. Nessa abordagem valoriza-se o contato direto e prolongado do pesquisador com o ambiente e a situação que está sendo estudada (MINAYO, 2012).

No que se refere aos objetivos da pesquisa, esta, caracteriza-se como descritiva, visando descrever as possibilidades de uso das redes sociais nos processos de recrutamento e seleção nas organizações, 
incluindo vantagens, dificuldades e principais redes utilizadas. Quanto aos meios utilizados como fonte de pesquisa, foram feitos estudos bibliográficos e estudo de multicasos. Bibliográfico, devido à necessidade de uma base teórica embasada em pesquisas já realizadas, aplicadas e comprovadas por autores. Estudo de multicasos, por necessitar de um maior aprofundamento e detalhamento das informações para que se possa chegar a um resultado mais preciso e próximo ao real, dentro do objetivo estabelecido na pesquisa. 0 propósito de um estudo de caso é reunir informações detalhadas e sistemáticas sobre um fenômeno. É um procedimento metodológico que enfatiza entendimentos contextuais, sem esquecer-se da representatividade (GIL, 2007).

A pesquisa foi realizada com três consultores de RH atuantes na região do Cariri, visto a determinação por acessibilidade, onde serão entrevistados profissionais com formação em Administração de Empresas, psicologia ou RH atuantes em consultoria na área de recrutamento e seleção na região do Cariri. A entrevista como instrumento de dados possui roteiro estruturado contendo onze perguntas, os dados coletados na entrevista foram anotados no momento da ocorrência da mesma, não havendo a necessidade de gravação.

Esta pesquisa propõe como método a análise de conteúdo, considerando a pesquisa qualitativa, enquanto método de organização e análise dos dados possui algumas características. Em que o seu foco é qualificar as vivências do sujeito, bem como suas percepções sobre determinado objeto e seus fenômenos. Segundo Gil (2010), esse método proporciona uma maior familiaridade com o problema que originou a obra, realizando-se um levantamento bibliográfico acerca dos assuntos que alicerçam a questão e seguindo-se de verificação da problemática apresentada, trazendo resultados que possam contribuir para o desenvolvimento de novas perspectivas e estudos sobre um determinado tema.

Os benefícios esperados com este estudo, tanto para a comunidade geral são relativos à geração de informações relevantes sobre as redes sociais como ferramenta de recrutamento e seleção, temática relativamente nova, no qual poderão conhecer melhor a importância desta ferramenta e aplicá-la tornando assim os processos de recrutamento e seleção mais ágeis, tanto para empresa quanto para os candidatos, otimizando os processos seletivos.

\section{RESULTADOS}

Com a finalidade de obter dados, que contemplem a argumentação teórica dos autores sobre a relevância do uso das redes sociais nos processos de recrutamento e seleção, foram realizadas entrevistas com pessoas que atuam diretamente nesta área ao possibilitar a contribuição para esse estudo, de modo a considerar as hipóteses levantadas por este trabalho.

Matos (2012) e outros autores utilizados neste trabalho versam sobre a importância da análise das redes sociais nos processos seletivos, ao defender que estas ajudam a complementar as informações sobre os candidatos e a esclarecer mais sobre suas personalidades. Assim, no intuito de verificar a aplicabilidade desta metodologia inovadora nos processos seletivos, no momento da pesquisa de campo, foi colocada como primeira pergunta: 
Tabela 1: Utilização das redes sociais no recrutamento e seleção

\begin{tabular}{|l|l|}
\hline A empresa utiliza as redes sociais para a realização de recrutamento e seleção? \\
\hline Empresa 1 & $\begin{array}{l}\text { Utilizamos o e-mail para o recebimento de currículos e as demais redes sociais para a divulgação das } \\
\text { vagas ofertadas. }\end{array}$ \\
\hline Empresa 2 & $\begin{array}{l}\text { Sim. Estamos na Era Pós-Digital e as redes sociais se constituem como importantes canais para } \\
\text { realização dos processos de recrutamento e seleção. }\end{array}$ \\
\hline Empresa 3 & Sim, analisamos o perfil dos candidatos para fins de seleção. \\
\hline
\end{tabular}

A partir das respostas acima é possível perceber que as redes vêm sendo utilizadas para a divulgação no momento do recrutamento e como critério decisivo na escolha durante a etapa de triagem da seleção, conforme o que Araújo (2012) alerta em sua pesquisa ao tratar do marketing pessoal no ambiente virtual. Além de contemplar a afirmativa de que o mercado vem se adaptando à inserção das novas metodologias tecnológicas como facilitadoras e/ou auxiliares dos processos seletivos. De forma complementar ao raciocínio foi realizada a seguinte pergunta que também é central para os objetivos de discussão deste artigo:

Tabela 2: Investigação das redes sociais dos candidatos.

\begin{tabular}{|l|l|}
\hline A empresa investiga as redes sociais dos candidatos nos processos seletivos? \\
\hline Empresa $\mathbf{1}$ & $\begin{array}{l}\text { É muito importante observar as redes sociais dos candidatos, afim de analisarmos o estilo de vida de } \\
\text { cada um e verificar se as informações fornecidas são verdadeiras. }\end{array}$ \\
\hline Empresa $\mathbf{2}$ & $\begin{array}{l}\text { Sim. As postagens se constituem elementos que podem ajudar na identificação de valores e } \\
\text { comportamentos importantes para assertividade do processo seletivo. }\end{array}$ \\
\hline Empresa 3 & Sim, para análise de comportamento, fazemos a triagem do perfil e dos conteúdos que eles seguem. \\
\hline
\end{tabular}

Segundo Zanuto (2010), o mercado de trabalho atual, procura profissionais que articulem competências técnicas e comportamentais, no sentido estratégico de que o uso da tecnologia também pode potencializar e transformar o trabalho da gestão de recursos humanos se fez necessário no decorrer do trabalho enumerar de acordo com os autores possíveis vantagens dessa estratégia nas organizações que também foram destacadas pelas respostas dos entrevistados com a seguinte pergunta:

Tabela 3: Vantagens ao utilizar as redes sociais no recrutamento e seleção.

\begin{tabular}{|l|l|}
\hline \multicolumn{2}{|l|}{ Quais as principais vantagens que a empresa tem ao utilizar as redes sociais em seus processos de recrutamento e seleção? } \\
\hline Empresa $\mathbf{1}$ & $\begin{array}{l}\text { Umas das principais vantagens é o tempo, pelas redes sociais o processo de recrutamento e seleção torna-se mais } \\
\text { prático. }\end{array}$ \\
\hline Empresa $\mathbf{2}$ & Agilidade, praticidade e constituição de evidências para as conclusões. \\
\hline Empresa $\mathbf{3}$ & Maior possibilidade de contratar um funcionário coerente com os princípios da empresa ao investigar seu perfil. \\
\hline
\end{tabular}

Considerando as respostas obtidas, é possível confirmar os apontamentos dos autores, tais como Fragoso (2017), que vem enfatizar a praticidade em gestão do tempo e informações na avaliação dos candidatos. Outro ponto importante para ser destacado no estudo, apesar das evidentes possibilidades e facilidades que a tecnologia vem em contribuir em diversos aspectos inclusive no trabalho, fez-se necessário questionar aos profissionais, quais as dificuldades de realizar processos seletivos utilizando redes sociais.

Tabela 4: Dificuldade do recrutamento pelas redes sociais.

\begin{tabular}{|l|l|}
\hline Quais as dificuldades de recrutar pelas redes sociais? \\
\hline Empresa 1 & A possibilidade de falsas informações contadas pelos candidatos. \\
\hline Empresa 2 & $\begin{array}{l}\text { Percebe-se que a interatividade dos candidatos pode ser maior no momento do recrutamento. Apesar } \\
\text { de usarmos estímulos, sentimos falta de ações que possam posicionar os candidatos no processo } \\
\text { seletivo. }\end{array}$ \\
\hline Empresa 3 & O tempo para aprofundar-se nas análises durante a fase de seleção. \\
\hline
\end{tabular}


Neto (2015) e Fragoso (2017) escrevem respectivamente sobre as possíveis dificuldades e vantagens da metodologia proposta neste trabalho. Após considerar pontos positivos e as desvantagens do uso destas tecnologias no recrutamento e na seleção de candidatos, é possível embasar o tema desta pesquisa na experiência dos entrevistados sobre a aplicabilidade das tecnologias em estudo para suas respectivas empresas no cotidiano de recrutamento de seleção em que as vantagens possuem destaque neste processo. No intuito de descrever como são utilizadas das redes sociais, nos processos seletivos, foi realizada a pergunta posterior:

Tabela 5: Como ocorre o processo seletivo através das redes sociais.

\begin{tabular}{|l|l|}
\hline Como normalmente ocorre o processo seletivo por meio de rede social? \\
\hline Empresa 1 & $\begin{array}{l}\text { Divulgamos uma vaga através do Facebook, Instagram e liberamos o e-mail para o recebimento destes } \\
\text { currículos, em seguida selecionamos o currículo que melhor se enquadra com o nosso perfil, } \\
\text { posteriormente, para fins de análise comportamental, analisamos as redes sociais dos candidatos. }\end{array}$ \\
\hline Empresa 2 & $\begin{array}{l}\text { Após o desenho da vaga/cargo, é elaborada uma arte com informações que são posicionadas de forma } \\
\text { estratégica para atrair os perfis aderentes. Feita a divulgação e montado o banco de recrutados, a etapa } \\
\text { seguinte é a triagem de currículos. Logo após a seleção é planejada (escolha de testes, dinâmicas e } \\
\text { métodos) e antes de ser executada consultamos as redes sociais dos candidatos na busca de evidências } \\
\text { sobre os valores e comportamentos que sejam aderentes com a vaga. Na sequência, a seleção é feita e } \\
\text { caso existam dúvidas geradas por meio da verificação nas redes sociais, existirá um momento para } \\
\text { abordar o candidato e esclarecê-las. }\end{array}$ \\
\hline Empresa 3 & $\begin{array}{l}\text { Os perfis nas redes sociais são como vitrines do que as pessoas pensam, fazem e compartilham, na fase } \\
\text { de seleção, geralmente anterior a entrevista, esses perfis valem como critério de contratação ou } \\
\text { descarte. }\end{array}$ \\
\hline
\end{tabular}

A partir destes dados e das pesquisas dos autores Araújo, Fragoso, Lemes, entre outros, é possível perceber como as redes tem aplicabilidade em ambos os processos, tanto recrutamento quanto na seleção, visto que destacamos no decorrer deste trabalho as possibilidades que estas têm a contribuir com o trabalho da gestão de recursos humanos. Considerando a perspectiva do entrevistado 3 (três), ao enfatizar a possibilidade de análise virtual do perfil dos candidatos, se faz necessário destacar na pergunta posterior:

Tabela 6: Aspectos negativos que chamam atenção nas redes sociais dos candidatos.

\begin{tabular}{|l|l|}
\hline Quais aspectos negativos chamam atenção na rede social do candidato que podem ser impeditivos para a sua contratação? \\
\hline Empresa 1 & $\begin{array}{l}\text { Um dos pontos negativos é quando encontramos postagens inadequadas, com incentivo a violência, } \\
\text { fotos comprometedoras e, isso pode interferir na contratação de um candidato. }\end{array}$ \\
\hline Empresa 2 & $\begin{array}{l}\text { Publicações com posicionamentos exagerados, que se reportem ao preconceito, exclusão social, } \\
\text { desrespeito aos direitos humanos, denegrindo a imagem de outras pessoas e de empresas, são os } \\
\text { principais aspectos que chamam atenção podendo gerar impeditivos para contratação. }\end{array}$ \\
\hline Empresa 3 & $\begin{array}{l}\text { Alienação, preconceito, falta de discussões na área que ele atua. Erros graves de escrita, } \\
\text { compartilhamento constante de fake news, discurso de ódio e incoerência. Superexposição, também } \\
\text { em relação a roupas e bebidas alcóolicas. }\end{array}$ \\
\hline
\end{tabular}

Algumas destas questões já haviam sido pontuadas por Almeri et al. (2013) no decorrer do referencial teórico, agora são confirmadas pela experiência profissional dos entrevistados. Na mesma perspectiva de identificar as possíveis características positivas que os recrutadores buscam nos candidatos ao analisarem os perfis, foi perguntado:

Tabela 7: Aspectos que chamam atenção de um recrutador nas redes sociais do candidato.

\begin{tabular}{|l|l|}
\hline O que chama mais atenção de um recrutador nas redes sociais dos candidatos? \\
\hline Empresa 1 & $\begin{array}{l}\text { O que chama mais atenção na rede social do candidato é sua postura diante dos seus conhecimentos } \\
\text { em suas postagens, isso é um ponto primordial que prezamos bastante. }\end{array}$ \\
\hline Empresa $\mathbf{2}$ & A forma de se posicionar nas publicações \\
\hline
\end{tabular}


Considerando a confirmação do uso das redes sociais nos processos seletivos pelas empresas dos profissionais entrevistados, bem como, sua importância para otimização deste trabalho, destacamos a partir de Matos (2012) e outros autores, algumas das redes sociais que as empresas normalmente analisam para avaliação de perfil e comportamento, logo, foi colocada esta questão para os entrevistados:

Tabela 8: Rede social mais utilizada no recrutamento.

\begin{tabular}{|l|l|}
\hline Qual a rede social é mais utilizada no recrutamento? \\
\hline Empresa $\mathbf{1}$ & $\begin{array}{l}\text { O e-mail para o recebimento de currículos, Instagram e Facebook para a divulgação das oportunidades } \\
\text { de trabalho. }\end{array}$ \\
\hline Empresa $\mathbf{2}$ & Instagram. \\
\hline Empresa $\mathbf{3}$ & Facebook, Instagram na análise das características da vida profissional e pessoal. \\
\hline
\end{tabular}

A partir da fala dos profissionais é possível conceber o Instagram como principal alvo das empresas para analisar as postagens e analisar o perfil comportamental dos candidatos, considerando que esta fase também é decisiva para contratação. Segundo Araújo (2012), o recrutador quer saber como o profissional se comporta e se articula nas redes sociais. Visto que as empresas estão aderindo a tal metodologia, é necessária a atenção do cuidado dos candidatos com o conteúdo exposto em suas redes sociais, nesse sentido, foi realizada a seguinte pergunta:

Tabela 9: Costume com o recrutamento e seleção online.

\begin{tabular}{|l|l|}
\hline Na sua percepção os candidatos já se acostumaram com o recrutamento e seleção online? \\
\hline Empresa 1 & $\begin{array}{l}\text { Os candidatos ainda não estão totalmente acostumados com o processo de recrutamento e seleção } \\
\text { o online, ainda há certo despreparo destes para estes processos, em que muitas vezes as informações } \\
\text { encontradas nas redes sociais são causas suficientes para descarte de candidatos. }\end{array}$ \\
\hline Empresa 2 & $\begin{array}{l}\text { Ainda não, pois existem muitas publicações inadequadas que ferem diretamente ao } \\
\text { profissionalismo, independente da área. }\end{array}$ \\
\hline Empresa 3 & Ainda é possível conceber como uma estratégia nova! \\
\hline
\end{tabular}

As respostas da pergunta a seguir colocam a utilização das redes sociais nos processos seletivos hoje tão necessários quanto às estratégias tradicionais, visto que podem se complementar ao atingir seus objetivos. Nesta perspectiva, Almeri et al. (2013) defendem que a verificação das redes é utilizada para respaldar informações pessoais prestadas durante o processo seletivo. Assim, a pergunta foi realizada da seguinte forma:

Tabela 1: Recrutamento e seleção on-line X Recrutamento e seleção tradicional.

\begin{tabular}{|l|l|}
\hline \multicolumn{2}{|l|}{$\begin{array}{l}\text { Na sua percepção os processos de recrutamento e seleção on-line são mais seguros e assertivos comparado aos processos } \\
\text { recrutamento e seleção tradicional? }\end{array}$} \\
\hline Empresa 1 & $\begin{array}{l}\text { Cada tem suas vantagens, o recrutamento e seleção online é muito prático, porém não dispensamos } \\
\text { totalmente o contato físico para secar a veracidade das informações. }\end{array}$ \\
\hline Empresa 2 & Não necessariamente, acho que na nossa realidade regional utilizar-se dos dois pode ser mais vantajoso. \\
\hline Empresa 3 & $\begin{array}{l}\text { Na minha visão, a assertividade dos processos seletivos depende da associação entre o perfil desejado } \\
\text { e as técnicas de seleção empregadas, sejam elas aplicadas de forma on-line ou presencial. }\end{array}$ \\
\hline
\end{tabular}

Outra ferramenta online utilizada pelos profissionais entrevistados, mencionada durante a entrevista, é o Linkedln, que teve destaque na a última pergunta, além do recebimento de currículos por email e Whatsapp. Para o recrutador ou empregador, a maior vantagem de redes como o Linkedin é a ampla 
oferta de candidatos em potencial enquanto uma rede específica de uso profissional focalizada nestas características objetivamente (FRAGOSO, 2017).

Tabela 11: Ferramentas on-line utilizadas para recrutar e selecionar talentos.

\begin{tabular}{|l|l|}
\hline Que outras ferramentas on-line você utiliza para recrutar e selecionar talentos? \\
\hline Empresa 1 & $\begin{array}{l}\text { Utilizamos o Linkedln para obter mais informações profissionais e as demais redes sociais como } \\
\text { Facebook, Instagram para analisar a vida pessoal dos candidatos. }\end{array}$ \\
\hline Empresa 2 & $\begin{array}{l}\text { Estamos começando a usar o currículo virtual recebido através do e-mail ou whatsapp. Os canais de } \\
\text { recebimento já se constituem pontos de avaliação sobre as estratégias de comunicação usadas pelos } \\
\text { candidatos. }\end{array}$ \\
\hline Empresa 3 & Linkedin. \\
\hline
\end{tabular}

Ao considerar a análise destes dados é importante salientar que as redes sociais, inseridas estrategicamente nos processos seletivos das organizações, possibilitam muitas vantagens, ao enfatizar a necessidade da eficácia destes processos, em um contexto de constantes transformações que a gestão de recursos humanos deve se adaptar ao lidar com seu capital humano.

\section{CONCLUSÕES}

Este artigo é resultado de uma pesquisa de multicasos empresariais baseando sua análise na argumentação teórica de autores que visam refletir sobre a presença e a influência das redes sociais digitais na sociedade e no trabalho, de modo a identificar sua contribuição enquanto ferramenta de comunicação e informação agregando nos processos seletivos. Logo, o objetivo deste trabalho, a partir da contextualização com a pesquisa de campo, foi analisar se as empresas têm utilizado as redes sociais enquanto instrumento de recrutamento e seleção, ao apontar suas vantagens, dificuldades e metodologias de aplicação nesse processo.

A partir da reflexão realizada neste trabalho, é possível perceber como a expansão da tecnologia configura uma nova possibilidade para os profissionais que trabalham com gestão de pessoas ao utilizar-se delas para extrair bons êxitos, facilidades e maior abrangência de seu trabalho. As redes sociais permitem às pessoas novos espaços sociais de relacionamento, de interação e exposição de ideias e das práticas cotidianas, estas novas formas de sociabilidade estão profundamente intrínsecas na vida contemporânea, inclusive no mundo do trabalho. Pois, como foi visto no decorrer do artigo, devido essa inserção do mundo virtual no social, é possível traçar perfis comportamentais pela análise das principais redes sociais utilizadas atualmente.

Além de considerar o uso dessas mídias sociais como meio de disseminação de informações em larga escala, como no caso do recrutamento em que as vagas podem ser divulgadas nas redes e nessa logística, as redes sociais estão inseridas desde o início do processo seletivo, do recrutamento à seleção, em que podem ser um fator extremamente decisivo pela análise das características dos candidatos considerando os objetivos e valores almejados pela empresa.

Nas discussões que permeiam a área de recursos humanos, a inovação e a eficácia são destacadas como uma constante necessidade destes profissionais, ao adaptar-se no cenário moderno e de constantes transformações. Tendo em vista a ascensão das tecnologias da informação e comunicação, confirmam-se as 
hipóteses levantadas por este artigo, em que as redes sociais podem ser vistas enquanto instrumento de trabalho na gestão, durante os processos de recrutamento e seleção promovendo esta adaptação que ao mesmo tempo, em que inova os itinerários de trabalho, possibilita eficácia para atingir resultados, mas já estão sendo utilizadas por muitas empresas, inclusive na região do Cariri.

Considerando a conclusão de que as empresas da região do Cariri têm utilizado as redes sociais enquanto instrumento de recrutamento e seleção, foi possível identificar o papel e as possibilidades de uso das redes sociais nos processos de recrutamento e seleção em organizações. Pois, segundo os profissionais das organizações que foram entrevistados, estas redes são fundamentais na análise de perfil dos candidatos e seleção dos mesmos considerando os objetivos e valores da empresa. Logo, esta ferramenta propõe maior facilidade/agilidade nas etapas do processo seletivo resultando em vantagens principalmente quanto à gestão do tempo. Como dificuldade foi pontuada a possibilidade de falsas informações contadas pelos candidatos, sendo destacada também que a parte presencial/tradicional da seleção deve ser realizada, visto que as informações de ambas as metodologias se completariam. Assim, foi destacado o Instagram como principal rede utilizada nestes processos, seguidos do Facebook e Linkedin, ficando assim como sugestão para próximas pesquisas fazerem um estudo ampliado do uso de uma rede específica nos processos de recrutamento e seleção.

\section{REFERÊNCIAS}

AFONSO, A. S.. Uma análise da utilização das redes sociais em ambientes corporativos. Dissertação (Mestrado em Tecnologias da Inteligência e Design Digital) - Universidade Católica de São Paulo, São Paulo, 2009.

ALMERI, T. M.; MARTINS, K. R.; PAULA, D. S.. O uso das redes sociais virtuais nos processos de recrutamento e seleção. Revista ECCOM, v.4, n.8, 2013.

ARAÚJO, G. H. D.. A Influência das redes sociais nos processos de recrutamento das empresas. In: CONGRESSO NACIONAL UNIVERSIDADE, EAD E SOFTWARE LIVRE. Anais. Belo horizonte: Universidade Federal de Minas Gerais, 2012.

BAYLÃO, A. L. S.; ROCHA, A. P. S.. A importância do processo de recrutamento e seleção de pessoal na organização empresarial. In: SIMPÓSIO DE EXCELÊNCIA EM GESTÃO E TECNOLOGIA, 11. Anais. Rio de Janeiro: 2014.

BREITENBACH, J. D.. As tecnologias da informação e comunicação na relação com a gestão estratégica escolar: uma análise segundo Pierre Lévy. Educação a Distância, Batatais, v.2, n.1, p.89-105, 2012.

CAETANO, A.; VALA, J.. Gestão de recursos humanos: contextos, processos e técnicas. 3 ed. Lisboa: RH, 2007.

CAPELLI, P.. Making the Most of On-Line Recruiting: How the Web Changes Recruiting. Harvard Business Review, v.79, n.3, 2001.

CASSIANO, C. N.; LIMA, L. C.; ZUPPANI, T. S.. A eficiência das redes sociais em processos de recrutamento organizacional. Navus, Florianópolis, v.6, n.2, p.52-67, 2016.
CASTELLS, M.. O poder da comunicação. Rio de Janeiro: Paz e Terra, 2015.

CASTELLS, M.. A Galáxia da Internet: Reflexões sobre a Internet, os Negócios e a Sociedade. Rio de Janeiro: Jorge Zahar, 2003.

CASTELLS, M.. A sociedade em rede. São Paulo: Paz e Terra, 1999.

CHIAVENATO, I.. Gestão de Pessoas: O novo papel dos recursos humanos nas organizações. 3 ed. Rio de Janeiro: Elsevier, 2010.

FREITAS, M. C. O.. As redes sociais utilizadas como ferramentas do recrutamento das PME de excelência em Lisboa. Dissertação (Doutorado) - Universidade Europeia, Lisboa, 2017.

FRAGOSO, A. I. M.. A influência das redes sociais nos processos de recrutamento e seleção. Dissertação (Doutorado) - Universidade do Porto, Porto, 2017.

GIL, A. C.. Métodos e técnicas de pesquisa social. 5 ed. São Paulo: Atlas, 2007.

GIL, A. C.. Como elaborar projetos de pesquisa. 5 ed. São Paulo: Atlas, 2010.

GIDDENS, A.. As Consequências da Modernidade. São Paulo: Universidade Estadual Paulista, 1991.

GIRARD, A.; FALLERY, B.. Human Resource Management on internet: new perspectives. The Journal Contemporary Management Research, v.4, n.2, p.97-120, 2010. 
GUIMARÃES, M. F., ARIEIRA, O. J.. O processo de recrutamento e seleção como uma ferramenta de gestão. Revista de Ciências Empresariais da Universidade Paranaense, v.6, n.2, 2005.

LEMES, A. G.; WESCHENFELDER, G. V.. A influência das redes sociais virtuais nos processos de recrutamento e seleção. Revista de Negócios da Cesuca, p.19-39, 2015.

LEMOS, A.. Cibercultura e Mobilidade: A Era da Conexão. In: CONGRESSO BRASILEIRO DE CIÊNCIAS DA COMUNICAÇÃO, 28. Anais. Rio de Janeiro: Universidade do Estado do Rio de Janeiro, 2005.

LEVY, P.. Cyberdemocratie. Paris: Odile Jacob, 2002.

LORENZO-ROMERO, C.; GÓMEZ-BORJA, M. Ã.; ALARCÓNDEL-AMO, M. C.. Redes sociales virtuales, ¿de qué depende su uso en España?. Revista Innovar Journal, v.21, n.41, p.145-157, 2011

MATOS, N.. Ferramenta complementar: empresas utilizam as redes sociais para otimizar processos em gestão de pessoas. 2012.

MARRAS, J. P.. Administração de Recursos Humanos: do operacional ao estratégico. 3 ed. São Paulo: Futura, 2000.

MARQUES, V.. Redes sociais 360: Como comunicar online. Coimbra: Conjuntura Actual, 2017.

MARTINS, J.. Recursos Humanos. Porto Velho: Faculdade de Ciências Humanas, Exatas e Letras de Rondônia, 2007.
MINAYO, M. C. S.. Pesquisa Social: teoria, método e criatividade. Petrópolis: Vozes; 2012.

MIRA, J. E.; BODONI, P. S. B.. Os impactos das redes sociais virtuais nas relações de jovens e adultos no ambiente acadêmico nacional. Revista de Educação, Faculdade de Bauru, v.14, n.17, p.103-115, 2011.

MITTER, G. V.; ORLANDINI, J. M.. Recrutamento online/internet. Revista de Ciências Empresariais: Maringá Management, v.2, n.2, p.19-34, 2005.

NETO, R. A. S.; DIAS, G. F.; RAMOS, A. S. M.; MARTINS, I. F. O.; NETO, M. V. S.. Recrutamento e Seleção nas Redes Sociais: A Percepção dos Estudantes de Administração da UFRN. Portal Metodista de Periódicos Científicos e Acadêmicos, São Paulo, v.11, n. 22, 2015.

REIS, F. L.. Recrutamento, Seleção e Integração. Lisboa: RH 2010.

RECUERO, R.. Redes Sociais na Internet. Porto Alegre: Sulina, 2009.

ROZENBLUM, T.. Tomar decisões de contratação usando o Facebook: como os candidatos são avaliados. Dissertação (Mestrado em Psicologia) - Universidade Estadual de San Jose, San Jose, 2012.

ZANUTO, M. S.. Recrutamento e seleção de talentos. Monografia (Graduação) - Lins, 2010.

A CBPC - Companhia Brasileira de Produção Científica (CNPJ: 11.221.422/0001-03) detém os direitos materiais desta publicação. Os direitos referem-se à publicação do trabalho em qualquer parte do mundo, incluindo os direitos às renovaç̃oses, expansões e disseminações da contribuiç̃o, bem como outros direitos subsidiários. Todos os trabalhos publicados eletronicamente poderão posteriormente ser publicados em coletâneas impressas sob coordenação da Cognitionis Publishing, da Companhia Brasileira de Produção Científica e seus parceiros autorizados. Os (as) autores (as) preservam os direitos autorais, mas não têm permissão para a publicação da contribuição em outro meio, impresso ou digital, em português ou em tradução. 